\title{
Systemic lupus erythematosus without clinical renal abnormalities: renal biopsy findings and clinical course
}

\author{
JAMES R O'DELL, ${ }^{1}$ ROBERT C HAYS, ${ }^{1}$ STEPHEN J GUGGENHEIM, ${ }^{23} 4$ \\ AND JAMES C STEIGERWALD
}

From the Divisions of ${ }^{1}$ Rheumatology and ${ }^{2}$ Nephrology, and the ${ }^{3}$ Department of Pathology, University of Colorado Health Sciences Center; and the ${ }^{4}$ Denver Veterans Administration Medical Center, Denver, Colorado, USA

SUMMARY The extent and significance of renal biopsy abnormalities in patients with systemic lupus erythematosus (SLE) without clinical renal abnormalities is controversial. We report 11 consecutive SLE patients who were biopsied without clinical renal abnormalities. All 11 patients had mesangial changes either by light microscopy or by immunofluorescent staining, and none had changes of focal or diffuse proliferative glomerulonephritis. Additionally none had deterioration of renal function during the mean follow-up period of $6 \cdot 3$ years.

Key words: mesangial, glomerulonephritis.

The presence or absence of renal disease is probably the single most important factor determining prognosis in systemic lupus erythematosus. ${ }^{12}$ Clinical renal disease is present in approximately $50 \%$ of patients with SLE, ${ }^{3-5}$ and renal biopsy abnormalities can be found in nearly all SLE patients. ${ }^{6-8}$ The extent and significance of renal biopsy abnormalities particularly in the group of patients without clinical renal abnormalities is controversial.

It has been suggested that if renal biopsies are done on patients without clinical renal abnormalities diffuse proliferative glomerulonephritis (DPGN) will be found in over $40 \%$ of patients and focal proliferative glomerulonephritis (FPGN) in a similar percentage. ${ }^{8}$ Because of these reports showing an impressively high incidence of significant glomerular lesions in SLE patients without clinical renal abnormalities, some have suggested that all patients with SLE should be biopsied at the time of diagnosis to record the extent of glomerular involvement and to determine therapy. ${ }^{8}$

The purpose of this study was first to determine the incidence of various renal biopsy findings in SLE patients without clinical evidence of renal abnorma-

Accepted for publication 10 December 1984.

Correspondence to Dr James R O'Dell, Assistant Professor of Internal Medicine, Section of Rheumatology and Immunology, University of Nebraska Medical Center, 42nd and Dewey Avenue, Omaha, Nebraska 68105, USA. lities and secondly to obtain information on the clinical course of SLE patients in this category.

\section{Patients and methods}

PATIENT SELECTION

Records from all SLE patients whose renal biopsies were read at the Denver Veterans Administration Medical Center (VAMC) during 1976 and 1977 were reviewed. These years were chosen in an attempt to obtain a mean follow up for this group of patients of five years. The Denver VAMC was a referral laboratory for renal biopsies done at all the teaching hospitals of the University of Colorado Health Sciences Center and at many surrounding hospitals, consequently not all of the patients included in this study were biopsied at or followed up by the University of Colorado Health Sciences Center. Patients were excluded if adequate renal tissue was not available for light microscopy (LM) and for immunofluorescence (IF) studies. Electron microscopy was also available in 10 of 11 patients. Patients were also excluded if on retrospective review inadequate data were available to assess renal function at the time of biopsy or if the diagnosis of SLE could not be substantiated (see below).

An extensive retrospective review of the patient's medical records was performed when such records were available. If the records were not available, 
information was obtained by contacting the patients' physicians or in some cases the patients themselves. Records were reviewed in an attempt to report the presence or absence of clinical renal disease at the time of biopsy and to obtain follow-up information on this group of patients in terms of renal functions and survival.

CLINICAL RENAL DISEASE

Clinical renal disease was defined as a serum creatinine $(\mathrm{Cr})$ of $1.5 \mathrm{mg} / \mathrm{dl}(133 \mu \mathrm{mol} / \mathrm{l})$ or greater for males or $1.2 \mathrm{mg} / \mathrm{dl}(106 \mu \mathrm{mol} / \mathrm{l})$ for females, proteinuria greater than $200 \mathrm{mg} / 24 \mathrm{~h}$, or active sediment (greater than five red blood cells or white blood cells/high power field or cellular casts). Of the 46 patients included in this study 35 had clinical renal disease and 11 did not.

DIAGNOSIS OF SLE

All patients included in this study fulfilled at least four of the 11 new revised American Rheumatism Association (ARA) criteria suggested for the diagnosis of SLE. ${ }^{9}$

\section{HISTOLOGICAL CLASSIFICATION OF KIDNEY BIOPSIES}

All biopsies were reviewed by at least three of the authors and this always included a renal pathologist (SG). Biopsies on the 11 patients without clinical evidence of renal disease were reviewed in conjunction with the rest of the 46 biopsies. Based on the histological changes present on examination by LM biopsies were categorised according to a classification proposed by the World Health Organisation ${ }^{10}$ : (1) normal or minimal change; (2) mesangial proliferation only; (3) focal proliferative glomerulonephritis (FPGN); (4) diffuse proliferative glomerulonephritis (DPGN); and (5) membranous glomerulopathy.

\section{Results}

\section{PATIENT PROFILE}

Forty-six patients with systemic lupus erythematosus had renal biopsies read at our institution during 1976-7. Eleven of these patients had no clinical evidence of renal disease at the time of biopsy nor had they previously had evidence of renal disease. These 11 patients are the focus of this article.

This group of 11 patients consisted of nine females and two males. Mean age at the time of renal biospy was 26 years (Table 1) with a range of 14-55 years. Mean duration of SLE at the time of biopsy was 2.5 years with a range of $0-5$ years. Six of the patients had had SLE diagnosed for at least two years at the time of the renal biopsy. Mean follow up for this
Table 1 Patient profile*

\begin{tabular}{|c|c|c|}
\hline & $M e a n \pm S E$ (years) & Range (years \\
\hline Age & $26 \pm 3 \cdot 2$ & $14-55$ \\
\hline $\begin{array}{l}\text { Duration of SLE at } \\
\text { time of biopsy }\end{array}$ & $2 \cdot 5 \pm 0.6$ & $0-5$ \\
\hline Follow up & $6 \cdot 3 \pm 0 \cdot 2$ & $4 \cdot 7-7 \cdot 0$ \\
\hline
\end{tabular}

group of patients was $6 \cdot 3$ years with a range of $4 \cdot 7-\dot{\bar{Z}}$ years.

Renal biopsies were obtained in this group ot patients either as part of another protocol which wa $\bar{\Omega}$ attempting to correlate skin and renal biopsyt findings ${ }^{11}$ (four patients) or in most cases, because ip was felt by the physicians caring for the patients at that time (1976-7) that most or all SLE patients should have renal biopsies.

\section{CLINICAL CHARACTERISTICS}

Table 2 shows the clinical characteristics of thi $\widehat{\Im}^{\mathrm{B}}$ group of patients. All patients had at least fouro criteria for the diagnosis of SLE, and the meary number of criteria for this series was five. Serumo creatinines were normal in all patients at the time of biopsy with a mean of $0.9 \mathrm{mg} / \mathrm{dl}(80 \mu \mathrm{mol} / \mathrm{l})$ and remained normal for all patients throughout the study, with a mean at follow up of $0.8 \mathrm{mg} / \mathrm{dl}(7 \mathrm{D}$ $\mu \mathrm{mol} / 1)$. Proteinuria was never greater than 200 $\mathrm{mg} / 24 \mathrm{~h}$ for any patient at any time during the stude्? except for patient 10 who had transient nephrotic range proteinuria in association with bacterial en docarditis. The proteinuria in this patient lates resolved and her creatinine remained normal. Alf patients were alive with normal renal function at the last available follow up, again with the single exception of patient 10 who died 4.7 years afte $\bar{B}$ biopsy as a result of bacterial endocarditis. Rena $\$$ function was normal at the time of death in this patient. Kaplan-Meier survival analysis for cen sored data showed a six-year predicted survival o. $91 \%$ for this group of patients.

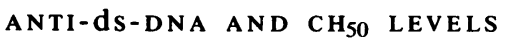

Table 3 shows the anti-ds-DNA antibody and $\mathrm{CH}_{5}$ levels in this group of patients. Anti-ds-DNA antibodies were obtained by the Farr assay with binding of less than $10 \%$ considered normal. Twछे patients had normal anti-ds-DNA antibody anç $\mathrm{CH}_{50}$ levels, seven patients had either raised anti-ds=0 DNA antibody levels or decreased $\mathrm{CH}_{50}$ levels, an $\bar{\Phi}$ two patients had both increased anti-ds-DNA anti疋 body levels and decreased $\mathrm{CH}_{50}$ levels. Althougl raised levels of anti-ds-DNA antibodies were pre sent in over half of this group, in most cases 
Table 2 Clinical characteristics

\begin{tabular}{|c|c|c|c|c|c|}
\hline \multirow[t]{2}{*}{ Patient } & \multirow{2}{*}{$\begin{array}{l}\text { Follow up } \\
\text { (years) }\end{array}$} & \multirow{2}{*}{$\begin{array}{l}\text { Criteria } \\
\text { for } S L E\end{array}$} & \multicolumn{2}{|c|}{ Serum creatinines $(\mathrm{mg} / \mathrm{dl})$} & \multirow[t]{2}{*}{ Status } \\
\hline & & & $B x^{*}$ & $F / u^{*}$ & \\
\hline 1 & $7 \cdot 0$ & 4 & $1 \cdot 0$ & $1 \cdot 1$ & Alive \\
\hline 2 & $6 \cdot 9$ & 6 & 0.7 & 0.7 & Alive \\
\hline 3 & $6 \cdot 3$ & 5 & $0 \cdot 5$ & $0 \cdot 9$ & Alive \\
\hline 4 & $6 \cdot 9$ & 4 & $0 \cdot 8$ & 0.9 & Alive \\
\hline 5 & $6 \cdot 9$ & 5 & $1 \cdot 1$ & 1.0 & Alive \\
\hline 6 & $6 \cdot 5$ & 4 & $0 \cdot 8$ & $0 \cdot 6$ & Alive \\
\hline 7 & $5 \cdot 0$ & 5 & $0 \cdot 9$ & $0 \cdot 9$ & Alive \\
\hline 8 & $6 \cdot 1$ & 4 & $0 \cdot 6$ & $0 \cdot 7$ & Alive \\
\hline 9 & $6 \cdot 8$ & 6 & 0.9 & $0 \cdot 8$ & Alive \\
\hline 10 & $4 \cdot 7$ & 7 & $1 \cdot 1$ & $0 \cdot 6$ & Dead \\
\hline 11 & $5 \cdot 6$ & 5 & $0 \cdot 9$ & $0 \cdot 8$ & Alive \\
\hline Mean \pm SLE & $6 \cdot 3 \pm 0 \cdot 2$ & $5 \cdot 0 \pm 0 \cdot 3$ & $0 \cdot 9 \pm 0 \cdot 1$ & $0 \cdot 8 \pm 0 \cdot 1$ & $91 \% 6$ years $t$ \\
\hline
\end{tabular}

${ }^{*} \mathrm{Bx}=$ at time of biopsy; $\mathrm{F} / \mathrm{u}=$ at follow up.

†Kaplan-Meier predicted a six year survival period.

SI conversion: creatinine $\mathrm{mg} / \mathrm{dl} \times 88 \cdot 4=\mu \mathrm{mol} / \mathrm{l}$.

Table 3 Anti-ds-DNA antibody and $\mathrm{CH}_{50}$ levels at biopsy

\begin{tabular}{lcl}
\hline Patient & $\begin{array}{l}\text { Anti-ds-DNA antibody }{ }^{*} \\
(\% \text { binding) }\end{array}$ & $\mathrm{CH}_{50}$ \\
\hline 1 & 1 & Normal ${ }^{\dagger}$ \\
2 & 18 & Normal \\
3 & 22 & Normal \\
4 & 10 & Decreased \\
5 & 21 & Normal \\
6 & 13 & Decreased \\
7 & 9 & Decreased \\
8 & NA & Decreased \\
9 & 68 & Decreased \\
10 & 1 & Normal \\
11 & 11 & Normal \\
\hline
\end{tabular}

*Anti-ds-DNA antibody levels were obtained by Farr assay. +Normal $=<10 \%$ binding.

$\mathrm{NA}=$ not available.

increases were mild and only one patient had an anti-ds-DNA antibody binding greater than $30 \%$ (patient 9).

\section{RENAL BIOPSY FINDINGS}

Table 4 shows the renal biopsy findings in this group of patients. By light microscopy three patients had normal biopsies and eight patients had only mesangial proliferation. None of these patients had changes of focal or diffuse proliferative glomerulonephritis.

Immunofluoresence was done for Ig and $\mathrm{C} 3$ deposition and intensity was scored from $1+$ to $3+$. Surprisingly two patients, Nos 4 and 5 , despite mesangial changes on light microscopy were completely negative for immunofluorescence. In the patients who did have immunofluorescence this was limited to the mesangium, except for patients 7, 9, and 10 who had $1+$ basement membrane staining.

Thus all 11 of these SLE patients without clinical evidence of renal disease had mesangial changes either by light microscopy or on immunofluorescent staining, further substantiating the belief that regardless of the clinical situation almost all patients with systemic lupus erythematosus will have renal biopsy abnormalities.

Electron microscopic evaluation was also performed on 10 of 11 biopsy specimens. Electron dense deposits when present were limited to the mesangium in all but two patients, Nos 4 and 11, in whose biopsy specimens there were rare subendothelial deposits.

Table 4 Renal biopsy findings

\begin{tabular}{lllll}
\hline Patient & $\begin{array}{l}\text { Classification } \\
\text { by Light } \\
\text { microscopy }\end{array}$ & $\begin{array}{l}\text { Mesangial } \\
\text { immunofluorescence }\end{array}$ & $\begin{array}{l}\text { Mesangial } \\
\text { EM deposits }\end{array}$ \\
\cline { 3 - 5 } & & Ig & $C 3$ & \\
\cline { 1 - 4 } 1 & Normal & + & + & 0 \\
2 & Normal & ++ & ++ & 0 \\
3 & Normal & ++ & +++ & + \\
4 & Mesangial & 0 & 0 & $++(\mathrm{SE}+)^{\dagger}$ \\
5 & Mesangial & 0 & 0 & 0 \\
6 & Mesangial & +++ & +++ & ++ \\
7 & Mesangial & $++(+\mathrm{B})^{*}$ & +++ & ++ \\
8 & Mesangial & + & + & + \\
9 & Mesangial & $+++(+\mathrm{B})^{*}+++(+\mathrm{B})^{*}$ & Not done \\
10 & Mesangial & $0(+\mathrm{B})^{*}$ & + & 0 \\
11 & Mesangial & +++ & +++ & $+++(\mathrm{SE}+) \dagger$ \\
\hline
\end{tabular}

$*+B=1+$ basement membrane staining.

$+\mathrm{SE}+=$ rare subendothelial deposits. 


\section{Discussion}

The incidence and extent of significant renal pathology that is found by renal biopsy of SLE patients without evidence of clinical renal abnormalities is controversial. $^{8}$ There is little or no disagreement in the literature about the fact that almost all patients with SLE regardless of the clinical situation will have mesangial changes on light microscopy or immunoglobulin or complement deposition by immunofluorescence.$^{6-8}$ Multiple investigators have found that $90-100 \%$ of SLE patients even in the absence of clinical renal abnormalities will have mesangial abnormalities on biopsy. Our study is in agreement with these reports, as all 11 of our patients despite the absence of any clinical renal abnormalities had mesangial changes either by light microscopy (eight of 11) or by immunofluorescence (nine of 11), with six of 11 having changes by both methods.

The reported incidence of significant renal pathology (FPGN or DPGN) in this group of SLE patients (those without clinical renal disease) ranges from 0 to $88 \%{ }^{8}{ }^{12-19}$ Previous reports have said that most of these patients have normal histology, minimal abnormalities, or mesangial nephropathy. However, Mahajan et al. reporting on biopsies of 27 patients with SLE without clinical renal abnormalities (criteria similar to ours), found DPGN in $12(44 \%)$ of these patients and focal disease in another 12 $(44 \%) .{ }^{8}$ This is the largest published series on this group of patients and led to the idea that all SLE patients regardless of the clinical findings should have renal biopsies because pathology worthy of treatment might be found.

We have reported on 11 consecutive patients with SLE who had renal biopsies without clinical renal abnormalities. Three had normal biopsies by light microscopy and eight had mesangial changes only. None of the patients in our series had DPGN or FPGN. These findings are drastically different from those of Mahajan et al. ${ }^{8}$ There are many possible explanations of the discrepancies between these two studies. Mahajan's series was published at a time before mesangial disease was an accepted category, and therefore these authors do not include this biopsy category in their classification. It is therefore unclear which of the patients in their series would have been classified as mesangial. Some of the patients in their focal group might be classified as mesangial, but it is very unlikely that the inclusion of a mesangial category would change the classification of most of the patients in their DPGN group, as most had an impressive degree of subendothelial deposits and inflammatory changes.

Patient selection is another possible explanation of the differences in these two series. Our patient were all biopsied in 1976 or 1977 and were generally. outpatients who were biopsied because their physies cians felt that biopsies were indicated. In the serieg by Mahajan et al. ${ }^{8}$ the patients with DPGN were biopsied from 1969 to 1975 (median 1971) fo reasons that are not stated and may have been inpatients, who therefore may have had more active disease. The difference in the year of biopsy may also be important, as it has been suggested thaP lupus is evolving into a more benign disease. ${ }^{20}$ The criteria for clinical renal disease at the time of biops were not significantly different in the two series However, in our series all patients who had pre viously had evidence of renal disease were excluded It was not clear if this was done in Mahajan's series and therefore potentially, patients who previousl had clinical renal abnormalities who were on thero apy could have been included in this group. The duration of SLE before biopsy is another possibly important factor in determining the incidence of significant renal pathology, as nephritis if it occurs usually does so in the first two years of SLE. $\frac{2 \mathrm{~d}}{\infty}$ However, the duration of SLE before biopsy in ouf series $2 \cdot 5 \pm 0 \cdot 6$ years $($ mean $\pm S E)$ did not diffep from that in Mahajan's series $2 \cdot 4 \pm 0 \cdot 3$ years.

It appears that the most likely explanations of the dramatically different findings in these two studie are the lack of a category for mesangial disease ing Mahajan's study, the possibility that some of Maha jan's patients may have previously had clinical rena? abnormalities, and the ever present differences in patient selection.

The most important questions, however, are: $(1 \stackrel{\circ}{\circ}$ In SLE patients without evidence of clinical rena市 abnormalities do renal biopsy findings have proge nostic significance? (2) If renal biopsy findings have prognostic significance, is therapeutic interventio effective in altering outcome and, if so, is it more effective before clinical evidence of renal disease develops? It has been shown many times that clinicat findings at the time of biopsy are more reliable that biopsy findings as predictors of prognosis. ${ }^{22}{ }^{23}$ Therefore, the assumption of similar prognostie significance for a particular biopsy finding in patients without clinical renal abnormalities as foE those with clinical renal abnormalities is clearly unwarranted. Certainly the patients in our study d@्ठ very well clinically over a mean follow-up period of 6.3 years, but we are of course unable to commen? on patients in this category with DPGN, since noned of our patients had DPGN. Only one of the $1 \overline{0}^{\circ}$ patients in Mahajan's series ${ }^{8}$ with DPGN went on t\& develop renal failure five years after biopsy, on died of sepsis, and the other 10 had remained stables with a mean follow up of 3.6 years at the time of 
their report. The influence, if any, of therapy on prognosis is unknown, as therapy varied greatly in our study and is not commented on in the study by Mahajan et al. $^{8}$

In summary, renal biopsy abnormalities can be found in almost all SLE patients regardless of clinical findings. It would appear from our study, however, that significant renal pathology in patients without clinical renal abnormalities is rare. Thus renal biopsies are not likely to influence management in this group of patients at this time. Longterm prospective controlled studies with large patient numbers would be needed to answer questions about prognostic and therapeutic significance of renal biopsy findings in this group of patients but do not appear warranted at this time.

The authors gratefully acknowledge the assistance of Ms Gene Wu and Ms Lucie Case in the preparation of this manuscript.

\section{References}

1 Karsh J, Klippel J H, Balow J E, Decker J L. Mortality in lupus nephritis. Arthritis Rheum 1979; 22: 764-9.

2 Rosner S, Ginzler E M, Diamond H S, et al. A multicenter study of outcome in systemic lupus erythematosus. II. Cause of death. Arthritis Rheum 1982; 25: 612-7.

3 Dubois E L. Lupus erythematosus. 2nd ed. New York: McGraw-Hill, 1974.

4 Dubois E L, Tuffanelli D L. Clinical manifestations of systemic lupus erythematosus: computer analysis of 520 cases. JAMA 1964; 190: 104-11.

5 Rothfield N G, McClusky R T, Baldwin D S. Renal disease in systemic lupus erythematosus. N Engl J Med 1963; 269: 537-44.

6 Dillard M G, Tillman R L, Sampson C C. Lupus nephritis: correlations between clinical course and presence of electrondense deposits. Lab Invest 1975; 32: 261-9.

7 Houghton D, Bennett W, Bardana E, et al. Silent renal involvement in systemic lupus erythematosus. Kidney Int 1975; 8: 449 .

8 Mahajan S K, Ordonez N G, Feitelson P J, Lim V S, Spargo B H, Katz A L. Lupus nephropathy without clinical renal involvement. Medicine (Baltimore) 1977; 56: 493-501.

9 Tan E M, Cohen A S, Fries J F, et al.The 1982 revised criteria for the classification of systemic lupus erythematosus. Arthritis Rheum 1982; 25: 1271-7.

10 McClusky R T. Lupus nephritis. In: Sommers S C, ed. Kidney pathology decennial 1966-1975. New York: Appleton-CenturyCrofts, 1975: 435 .

11 Morris R J, Guggenheim S J, McIntosh R M, Rubin R L, Kohler P F. Simultaneous immunologic studies of skin and kidney in systemic lupus erythematosus. Arthritis Rheum 1979; 22: $864-70$.

12 Hollcraft R M. Dubois E L. Lundberg G D, et al. Renal damage in systemic lupus erythematosus with normal renal function. I Rheumatol 1976; 3: 251-61.

13 Cruchaud A, Chenais F. Fournic G J, et al.Immune complex deposits in systemic lupus erythematosus kidney without histological or functional alterations. Eur J Clin Invest 1975; 5: 297-309.

14 Sinniah R, Feng P H. Lupus nephritis: correlation between light, electron microscopic and immunofluorescent findings and renal function. Clin Nephrol 1976; 6: 340-51.

15 Soffer L J. Southren A L, Weiner H E, Wolf R L. Renal manifestations of systemic lupus erythematosus: a clinical and pathologic study of 90 cases. Ann Intern Med 1961; 54: 215-28.

16 Bardana E J Jr, Harbeck R J, Hoffman A A, Pirofsky B, Carr $R$ I. The prognostic and therapeutic implications of DNA: antiDNA immune complexes in systemic lupus erythematosus (SLE). Am J Med 1975; 59: 515-22.

17 Bennett W, Houghton D. Bardana E, Striker G. Staging of renal involvement in systemic lupus erythematosus when clinical nephropathy is absent. Clin Res 1976; 24: 161A.

18 Dujovne I, Pollak V E, Pirani C L, Dillard M G. The distribution and character of glomerular deposits in systemic lupus erythematosus. Kidney Int 1972; 2: 33-50.

19 Zweiman B, Kornblum J, Cornog J, Hildreth E A. The prognosis of lupus nephritis. Role of clinico-pathologic correlations. Ann Intern Med 1968; 69: 441-53.

20 Albert D A, Hadler N M, Ropes M W. Does corticosteroid therapy affect the survival of patients with systemic lupus erythematosus? Arthritis Rheum 1979; 22: 945-53.

21 Estes D, Christian C L. The natural history of systemic lupus erythematosus by prospective analysis. Medicine (Baltimore) 1971; 50: 85-95.

22 Fries J F, Porta J, Liang M N. Marginal benefit of renal biopsy in systemic lupus erythematosus. Arch Intern Med 1978; 138: $1386-9$.

23 Whiting-O'Keefe Q, Henke J E, Shearn M A, Hopper J Jr, Biaua C G. Epstein $W V$. The information content from renal biopsy in systemic lupus erythematosus. Stepwise linear regression analysis. Ann Intern Med 1982; 96: 718-23. 